\title{
Efectos de las anomalías climáticas en la cobertura de nieve de los glaciares centrales del Perú
}

\author{
Effects of climate anomalies on the snow cover of the \\ Peruvian Central glaciers
}

\author{
Jacinto Arroyo Aliaga? \\ Universidad Continental \\ jarroyox@gmail.com
}

\author{
Pedro Gurmendi Párraga² \\ Universidad Continental
}

\author{
Elizabeth Machuca Manrique ${ }^{3}$ \\ Grupo de investigación en Ciencias \\ Ambientales y Terrestres
}

\section{RESUMEN}

Se definió como objetivo, identificar los efectos de anomalías climáticas en la cobertura de nieve de los glaciares centrales del Perú. Para el desarrollo de esta investigación se han utilizado los métodos del índice de precipitación estandarizada para el análisis de las anomalías climáticas; de la transformada rápida de Fourier para la identificación de la variabilidad climática, y el método de geoprocesamiento de imágenes satelitales Landsat. Algunos resultados son: Se identificaron cuatro anomalías negativas que corresponden a los años 1991 (extremadamente seco) y 1986, 2005, 2009 (muy seco) con tres anomalías positivas que corresponden a los años 1985, 2010 (extremadamente lluvioso); 1966 (muy lluviosol que influyeron en la pérdida y acumulación del manto de nieve del glaciar Huaytapallana. En el glaciar Pariaqaqa se encontró tres anomalías negativas de los años 1991 (Extremadamente seco); 1990, 2013 (muy seco) y cuatro anomalías positivas de los años 1972 y 2010 (extremadamente lluvioso); 1966 y 2011 (muy lluvioso); que influyeron positivamente en la acumulación del manto de nieve. Se concluye que la pérdida neta corresponde a 5 km2 en el glaciar Huaytapallana y 7 km2 en el glaciar Pariaqaqa. El incremento del manto de nieve del glaciar Huaytapallana y Pariaqaqa en los ciclos hidrológicos del 2010, 2011 y 2012 se debe a un aumento en las intensidades de las precipitaciones registradas durante estos años por cambios en los patrones de circulación atmosférica por fenómenos de El Niño Oscilación del Sur.

Palabras clave: Anomalías climáticas, desglaciación, glaciares

\begin{abstract}
The study aims to identify the effects of climate anomalies on the snow cover of the Peruvian Central glaciers. For the development of this research, the Standardized Precipitation Index of climatic anomalies was used for the analysis; the Fast Fourier Transform for climate variability identification; and Landsat satellite images for geoprocessing. The results showed four negative anomalies corresponding to the years 1991 (extremely dry) and 1986, 2005, 2009 (very dry) along with three positive anomalies corresponding to the years 1985, 2010 (extremely rainy), and 1966 (very rainy); that influenced the loss and accumulation of the Huaytapallana glacier snow cover. In the Pariaqaqa glacier, three negative anomalies in 1991 (extremely dry); 1990, 2013 (very dry) were found, and four positive anomalies in 1972 , 2010 (extremely rainy); and 1966, 2011 (very rainy); that positively influenced the accumulation of snow cover. As a conclusion, the net loss corresponds to 5 $\mathrm{km} 2$ in the Huaytapallana glacier and $7 \mathrm{~km} 2$ in the glacier of Pariaqaqa. The snow cover expansion that occurred in both glaciers in the hydrological cycles of 2010,2011 and 2012 is due to increases of rainfall intensities registered during those years as a result of changes in the atmospheric circulation patterns by the effect of EI Niño - Southern Oscillation.
\end{abstract}

Keywords: Climatic anomalies, deglaciation, glacier.

Historial del artículo:

Recibido: 10 de setiembre de 2014. Aprobado: 5 de mayo de 2015. Disponible en línea: 30 de junio de 2015

1 Docente de la Universidad Continental, investigador del Instituto Geofísico del Perú.

2 Docente de la Universidad Continental.

3 Investigadora del Grupo de Investigación en Ciencias Ambientales y Terrestres "GICAT". 


\section{INTRODUCCIÓN}

Investigaciones realizadas por Vuille (1) y Thompson (2) sobre el destino de los glaciares tropicales de Sudamérica confirman un proceso de desglaciación que se ha observado en glaciares de varios países. En el Perú, donde se concentra el $78 \%$ de los glaciares tropicales, existe la misma tendencia, como lo reportan Francou et al (3). La reducción monitoreada en los principales glaciares tropicales fue más del $20 \%$ durante los años 1970 a 1997, Bury et al (4). Pero en los Andes el proceso de disminución de los glaciares empezó desde el final de la pequeña edad de hielo en 1850, Georges (5), Francou et al (6). Pero el proceso de retiro se ha acelerado en las últimas décadas del siglo 20 como lo reportan Kaser y Georges (7).

Viulle y Bradley (8), Kaser y Osmaston (9), Racoviteanu (10), Mark y Seltzer (11) y Brandley ef al (12), asocian temporal, López et al (16).

La disminución de las masas glaciares en el tiempo ha conducido el nacimiento de nuevas lagunas consideradas como pro glaciares y esto a la vez ha generado el aumento en la superficie y el volumen de muchas lagunas existentes, Ames (17). También ha aumentado el número de avalanchas y derrumbes de glaciares de las zonas de acumulación, Fraser (18). Los peligros de una disminución de los flujos de agua que se vierten a los ríos es reportado por Mark y Seltzer (19), y las inundaciones que puedan ocasionarse en las temporadas de lluvia aumentarían su frecuencia por la pérdida de la masa de nieve que produce un efecto amortiguador.

Los glaciares tienen importancia ambiental, porque regulan los procesos climáticos, pero también tienen importancia económica y social por que proveen agua

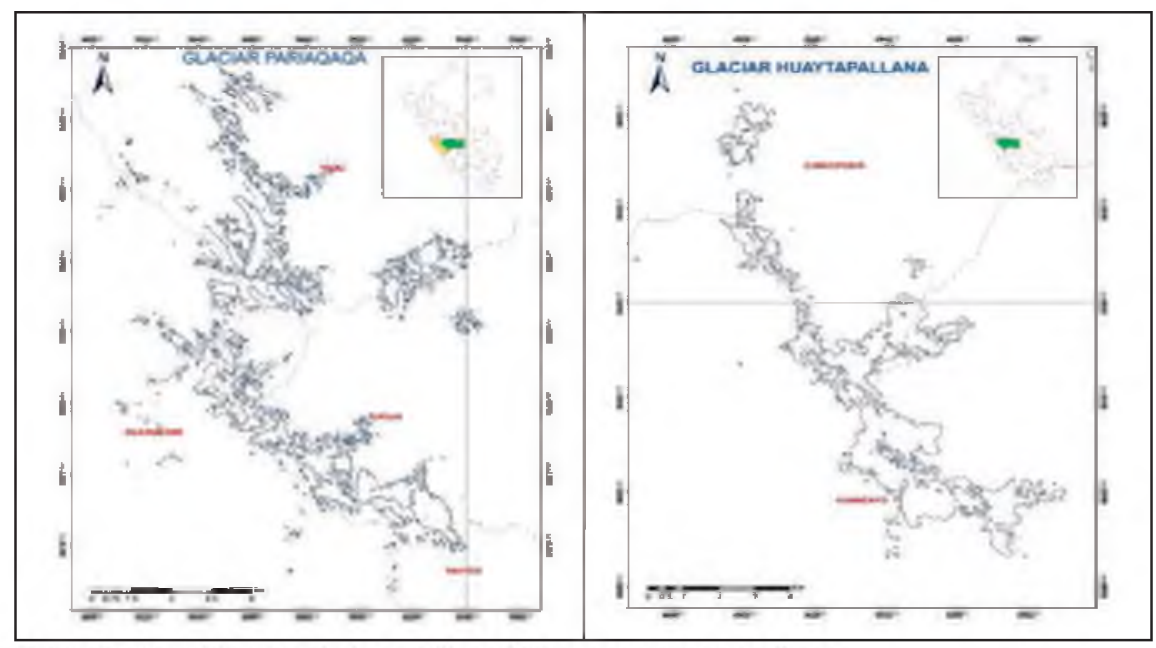

Figura $N^{\circ} 1$ : Ubicación de la cordillera Pariaqaqa y Huaytapallana.

la pérdida acelerada de glaciares al aumento de la temperatura del aire en toda la región de Sudamérica. El aumento de la temperatura del aire influye en la transferencia de calor de la masa glaciar que aumenta la presión de vapor de saturación, causando un aumento en la humedad específica y relativa, Chevalier et al (13). La fusión que conlleva un aumento de la disminución de masa glaciar es producto del flujo del calor latente por sublimación que es consumido en la pérdida de dicha masa, Sicart et al (14).

Los glaciares de la cordillera Huaytapallana se reporta en los estudios de Zubieta y Lagos (15), quienes indican que hubo una pérdida neta superior al $50 \%$ con respecto a 1956. Las anomalías negativas producto del fenómeno del niño aceleran la disminución de los glaciares y que tiene como consecuencia el enfriamiento del sistema que ocasiona anomalías positivas y genera un aumento de la masa glaciar a las poblaciones de ciudades. Estas características importantes son abordadas por Viulle (1) y Rabatel (20). En el Perú los glaciares como problema han sido reportados por Portocarrero (21), quien informa que los grandes desastres naturales por aludes y riadas se han producido en el Callejón de Huaylas matando a 25000 personas. Pero los glaciares de montaña de la parte central del Perú, aún no han sido abordados. Por lo que constituye la razón de investigación.

El estudio de las anomalías climáticas reportado por Arroyo (22), manifiesta que hay fenómenos que influyen en las precipitaciones. Lagos (23), manifiesta que son las anomalías climáticas derivadas del ENSO (El Niño Oscilación del Sur) que generan una deficiencia de precipitaciones, cuando se encuentra en la fase cálida y precipitaciones en exceso en la fase fría esta última conocida como la Niña. 
Sin embargo, los cambios de algunas regiones montañosas cercanas a los glaciares aún no se han estudiado en detalle en el Perú. Las variaciones en la cobertura de nieve de la Cordillera Huaytapallana (región Junín) y la Cordillera de Pariaqaqa (Límite entre Junín y Lima) que tienen montañas superiores a $5000 \mathrm{msnm}$ (figura $\mathrm{N}^{\circ}$ 1), responden a estas anomalías. Las variaciones y fluctuaciones que se han presentado durante los últimos años han estado conectadas a los fenómenos ENSO, el niño influye en la pérdida de masa glaciar, mientras que la niña genera una anomalía positiva como muestran las observaciones satelitales. Los glaciares de la cordillera Huaytapallana han mostrado recuperación de sus niveles de masa glaciar durante los ciclos hidrológicos de los años 2010-2013. Pero este comportamiento atípico tiene diferentes explicaciones debido a la circulación general de las masas de aire. ¿̇Cuáles son los efectos de las anomalías climáticas en la cobertura de nieve de los glaciares centrales del Perú?

El propósito de la investigación fue explicar los efectos de las anomalías climáticas en la cobertura de la nieve de los glaciares centrales del Perú. Relacionándolo con el régimen de precipitaciones, que puedan explicar las causas del incremento. Los cambios en el régimen de las precipitaciones son los factores que inciden en el incremento o disminución de la masa de nieve de los glaciares y cuyo comportamiento responde principalmente a condiciones atmosféricas regionales y locales conocidos como anomalías.

\section{MATERIAL Y MÉTODOS}

La cordillera Huaytapallana y la cordillera Pariaqaqa, están ubicadas en la cordillera oriental y occidental de los Andes centrales del Perú, la cordillera Huaytapallana forma parte del límite de las cuencas hidrográficas de los ríos Mantaro y Perené en la región Junín, es un sistema de glaciares de circo, caracterizado por la presencia de lagunas debido a la fusión de las masas de nieve y al retroceso glaciar que ha formado depresiones en dónde se ha depositado el agua; entre ellas Chuspicocha, Lasuntay y Cochagrande, las cuales están retenidas por un dique morrénico. El represamiento del Chuspicocha y Lasuntay es el principal aporte directo de descargas en los meses de estiaje al río Shullcas, principal abastecedor de agua a la ciudad de Huancayo, capital de la región Junín. La cordillera de Pariaqaqa forma parte de los límites de Junín y Lima y abastece a varias lagunas de la zona occidental.

Se analizó las imágenes satelitales disponibles del sensor Thematic Mapper (TM) y Enhanced Thematic Mapper (ETM +) de los archivos del Servicio Geológico de Estados Unidos (USGS, http://landsat.usgs.gov/). Se consideró los datos de Landsat ETM + y radiometría
TM para comparar. Las imágenes del sensor MSS, a partir del año 1975 hasta el año 1983 y a partir del año 1984 se utilizará TM. Un total de 30 imágenes se procesaron para el análisis de las áreas cubiertas de hielo y las ubicaciones de los límites de nieve desde el mismo periodo. Además se tomaron las imágenes en invierno por ser considerado seco (junio -setiembre), y porque la nubosidad es baja, además de presentar una cobertura mínima de nieve durante la temporada. Estos procesos redujeron los errores de clasificación de las áreas cubiertas de hielo y proporcionaron la clasificación de los límites de nieves.

Las imágenes proporcionadas por el USGS se procesaron para realizar una corrección estándar del terreno (nivel 1 T), que nos proporciona el índice radiométrico sistemático y de precisión geométrica. Mediante la incorporación de puntos de control, de un modelo de elevación digital (DEM). Después de la corrección geométrica, la cobertura de sombras de nubes fue manualmente digitalizada y eliminadas.

En el tratamiento de las imágenes satelitales se ha utilizado el método de cálculo de NDSI (Normalized Difference Snow Index), que es un índice análogo al NDVI (Normalized Difference Vegetation Index), el cual ajusta al límite de cobertura glaciar diferenciándola de la roca. Mediante las reflectancias de las bandas 2 (espectro visible) y las bandas 5 (SWIR), y tiene la siguiente ecuación.

$$
\text { NDSI }=\frac{T M 2-T M 5}{T M 2+T M 5}
$$

El valor umbral mínimo tomado a partir del cual se considera la transición de nieve a hielo, ha sido el elegido por el proyecto MODIS (Moderate Resolution Imaging Spectroradiometer) cifrado en 0,4 como lo reporta McFadden et al. (24), seleccionándose las imágenes de los meses de junio, por ser un mes donde el grado de perpetuidad de la masa glaciar es mayor, debido a las bajas temperaturas y ausencia precipitaciones, como por la ausencia de nubes.

También se realizó el análisis comparativo de cobertura glaciar de las imágenes de visualización libre, proporcionado por Google Earth que corresponde a las imágenes de Digital Globe de junio del año 1969 hasta el año 2014. Para el análisis del régimen de precipitación se han empleado los registros climáticos de dos estaciones meteorológicas de propiedad de ELECTROPERÚ (25), los cuales son más cercanos a la cordillera Huaytapallana y Pariaqaqa. También se han utilizado la técnica de conversión de nieve granular a $\mathrm{mm}$ equivalente de precipitación para diferenciar la acumulación neta de nieve (Figura $N^{\circ} 2$ ).

Las anomalías climáticas fueron obtenidas a partir de 
la utilización del método del Índice de Precipitación Estandarizada (SPI), que consiste en usar registros históricos de climatología, como base de comparación para una escala de tiempo dada propuesto por Nuñez et al (26) y consiste en obtener la diferencia de precipitación a partir de la media dividido entre la desviación estándar, el cual modifica la serie de precipitación para convertirlo en una distribución normal. Para la interpretación del SPI se adopta valores negativos y positivos consecutivos, alcanzando una intensidad de -1 o menor para la clasificación de sequía y de valores positivos superiores a 1 para periodos húmedos. Una vez que la distribución de anomalías de precipitación de una serie se ha transformado a una distribución normal, permite la obtención de valores válidos y comparables entre distintas estaciones meteorológicas. La expresión de valores se consigue en términos de probabilidad de ocurrencia de las anomalías.

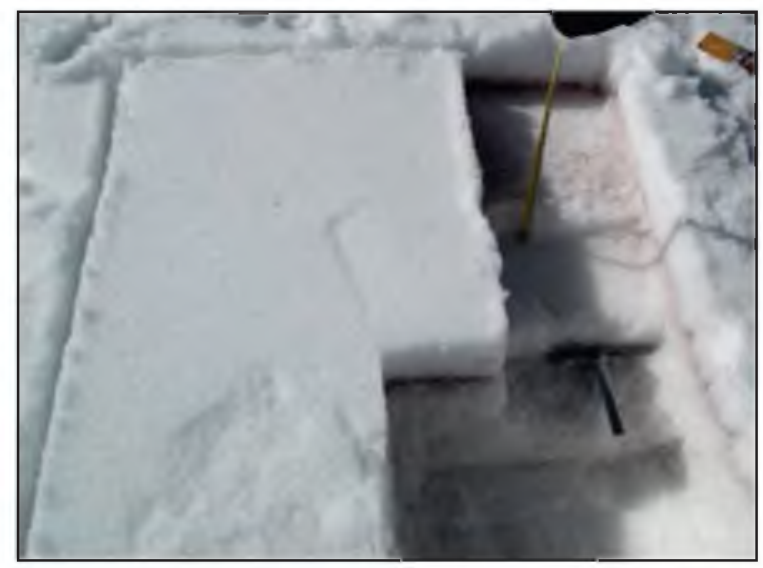

Figura $N^{\circ}$ 2: Perforaciones para determinar el volumen de masa acumulada.

\section{RESULTADOS}

\section{Anomalías climáticas}

Las anomalías climáticas del glaciar Pariaqaqa y Huaytapallana se presentan en la figura 3. La frecuencia de eventos que corresponde al glaciar Pariaqaqa se distribuye en 37 años normales, un año extremadamente seco (1991), un año categorizado como muy seco (1990) y tres años moderadamente seco $(1965,1967,2013)$. De igual manera de observa dos años extremadamente lluviosos (1972 y 2010), dos años muy lluviosos (1966 y 2011) y tres años moderadamente lluviosos (1966, 1973 y 2009).

La distribución de eventos para el glaciar Huaytapallana, corresponde a 33 años con precipitaciones normales un año extremadamente seco (1991), tres años muy $\operatorname{secos}(1986,2005$ y 2009) y tres años moderadamente
Tabla $N^{\circ}$ 1: Clasificación por el Método SPI.

\begin{tabular}{lc}
\hline Categoría & Valores SPI \\
\hline Extremadamente seco & Inferiores a -2 \\
Muy seco & $-1,5$ a $-1,99$ \\
Moderadamente seco & $-1,0$ a $-1,49$ \\
Normal & $-0,99$ a 0,99 \\
Moderadamente lluvioso & 1,00 a 1,49 \\
Muy lluvioso & 1,50 a 1,99 \\
Extremadamente lluvioso & Mayores a 2 \\
\hline
\end{tabular}

Fuente: NCAR (National Center for Atmospheric Research).

secos (1976, 1989 y 2013). Para eventos húmedos se registraron dos años extremamente lluviosos (1985 y 2010), un año muy lluvioso (1966) y seis años moderadamente lluviosos (1981, 1983, 1987, 1993, 2002 y 2008).

La figura $N^{\circ} 4$, presentan las anomalías registradas en la acumulación de mantos de nieve del glaciar Pariaqaqa y Huaytapallana. El año 1991 muestra una anomalía extremadamente seca para ambos glaciares y coincidentemente el año 2010 se presenta un evento extremadamente húmedo que permite acumular mantos de nieve muy significativamente. Las diferencias en los sistemas de acumulación muestran comportamientos que distinguen a ambos glaciares. Sin embargo, es el glaciar Huaytapallana que muestra mayores anomalías en la acumulación de nieve.

\section{Eventos atípicos}

La figura 5, muestra los eventos atípicos de las precipitaciones para la cordillera Pariaqaqa $y$ Huaytapallana. En la cordillera Pariaqaqa se encontró varios eventos atípicos en los meses de diciembre, enero y febrero. Para el mes de diciembre se encontró cuatro eventos anómalos positivos con precipitaciones superiores en dos desviaciones al tercer cuartil. El año 2009 (186 mm), 2010 (202 mm), 2011 (195 mm). También se encontró un evento anómalo negativo para el mes de diciembre en el año $1971(1,1 \mathrm{~mm})$. Para el mes de enero se encontraron seis eventos atípicos positivos y un evento negativo que corresponde al año $1991(59,1 \mathrm{~mm})$. Finalmente para el mes de febrero se encontró dos eventos atípicos positivos en los años $2010(190,7 \mathrm{~mm})$ y $2011(199,4 \mathrm{~mm})$ y un evento atípico negativo que corresponde al año 1965 (28,5 $\mathrm{mm})$.

Para la cordillera Huaytapallana, se encontró menores eventos atípicos en los meses de diciembre, enero y febrero. En el mes de enero se encontró dos eventos atípicos positivos que corresponde al año 2010 (190,7 $\mathrm{mm})$ y el 2011 (199,4 mm).

El evento atípico negativo fue el año 1965 (28,5 mm). 
Para el mes de enero se encontró un evento atípico positivo para el año 1977 (294,2 mm) y finalmente se encontró un evento atípico negativo para el mes de febrero que corresponde al año $1997(0 \mathrm{~mm})$.

\section{Efectos de las anomalías climáticas en la cobertura de nieve}

En la figura $N^{\circ} 6$, se presenta la regresión lineal entre las factor de cambio $\Delta$ cobertura $/ \Delta$ precipitación $=0,0145$ para el glaciar del Pariaqaqa y de $\Delta$ cobertura/ $\Delta$ precip itación $=0,0135$ para el glaciar Huaytapallana.

Cambios observados en la cobertura del manto de nieve del Huaytapallana por efectos de las anomalías climáticas del 2010 y 2012.

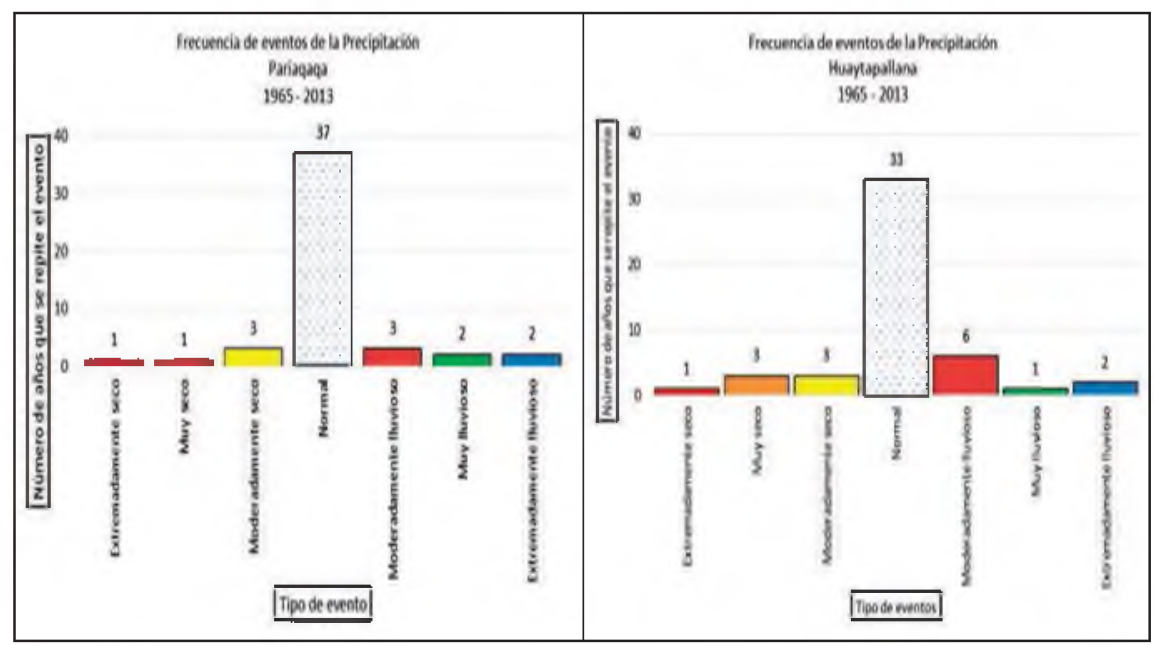

Figura $N^{\circ}$ 3: Distribución de frecuencia de eventos del glaciar Pariaqaqa y Huaytapallana.

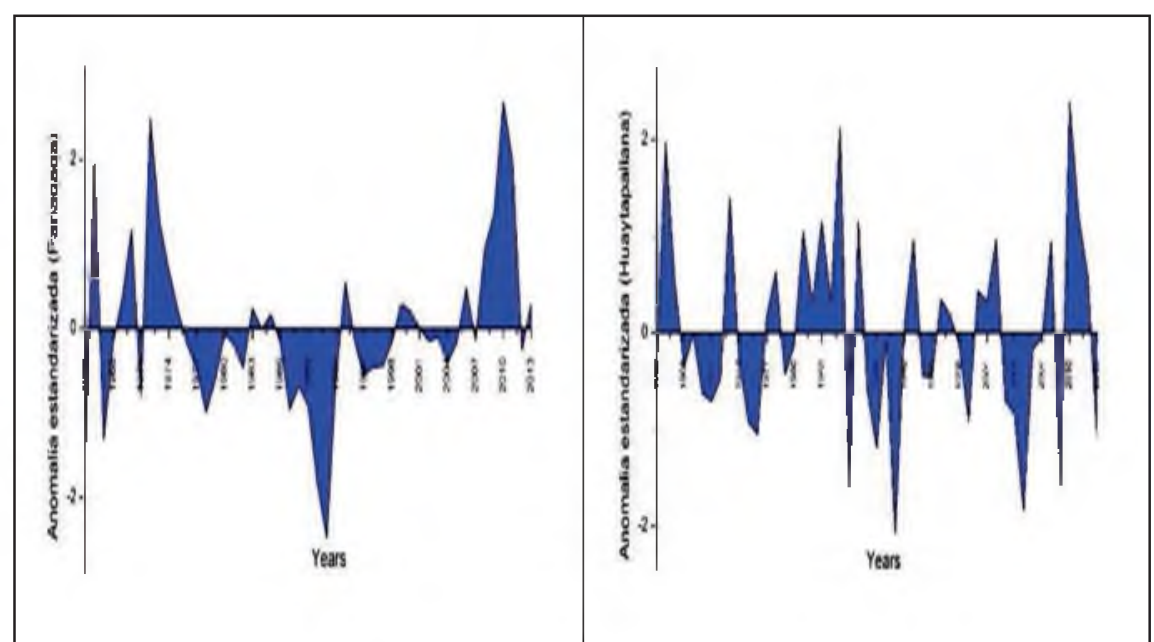

Figura $\mathrm{N}^{\circ}$ 4: Anomalía de acumulación de mantos de nieve del glaciar Pariaqaqa y glaciar Huaytapallana.

anomalías climáticas /variaciones de la precipitación en $\mathrm{mm}$ ) y la cobertura de nieve (variaciones del manto de nieve en $\mathrm{km} 2$ ).

Las anomalías de la precipitación explican el $55 \%$ de la cobertura del manto de nieve del glaciar Pariaqaqa y $64 \%$ del Huaytapallana. Una anomalía positiva influye en mayor cobertura $y$ un efecto negativo disminuye la masa del manto de nieve. Además el
La extensión de cobertura de masa glaciar entre dos momentos temporales que corresponden a imágenes satelitales del año 2010, considerado como el punto crítico de disminución de la cobertura y del 2012 como el punto de acumulación máxima registrada con respecto a la imagen del año 2010 son presentados en la figura 7 y 8 . Ambas imágenes se analizan con el régimen hídrico que corresponde al periodo del ciclo hidrológico 2009-2010 que se presenta en la figura 9 
y 10. Ambas imágenes muestran una disminución de las precipitaciones por debajo de su normal o patrón pluviométrico y el ciclo hidrológico que corresponde al periodo 201 1-2012, en relación a la normal climática. En el periodo del ciclo hidrológico 2010-2011, el régimen pluviométrico se incrementó en $50 \%$ sobre la normal pluviométrica conocida, factor quetiene relación con la recuperación de la cobertura de masa glaciar. Mientras que los periodos 2009-2010 corresponde a corresponde a dos periodos hidrológicos, de la fase de disminución crítica y aumento significativo en el 2012.

\section{Tendencia de la cobertura del manto de} nieve en el glaciar Huaytapallana.

En la figura $N^{\circ} 11$ y 12 , se compara dos periodos de análisis uno que corresponde a un punto crítico del año 2010 y la cobertura de masa glaciar del año

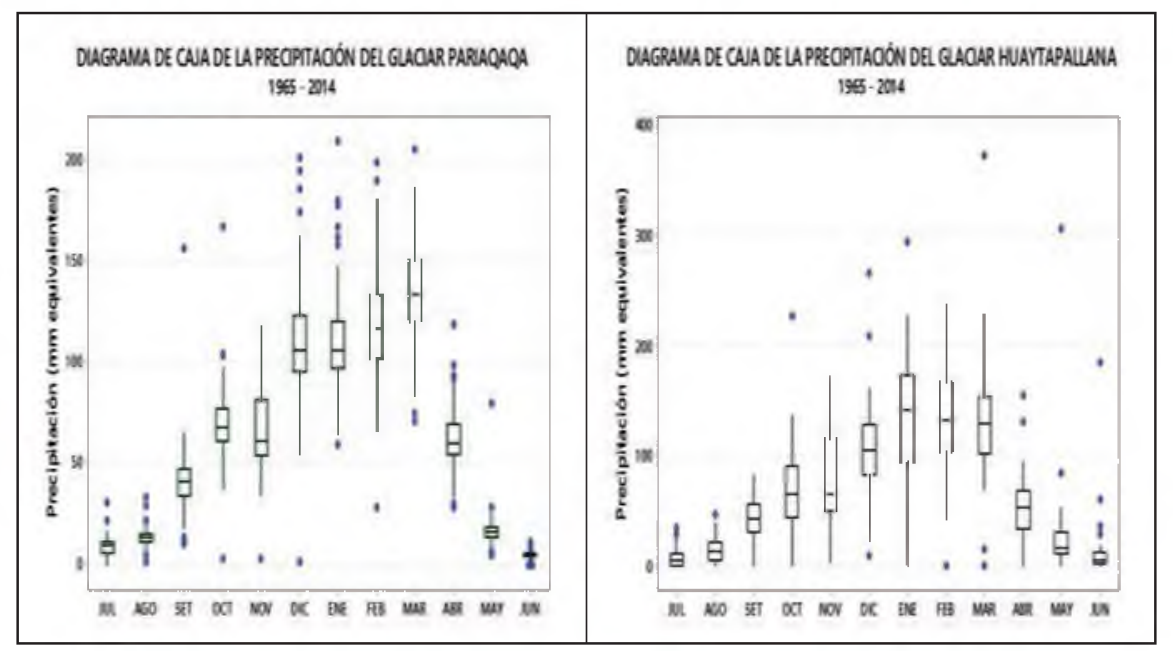

Figura $N^{\circ}$ 5: Fenómenos atípicos encontrados en el glaciar Pariaqaqa y Huaytapallana.

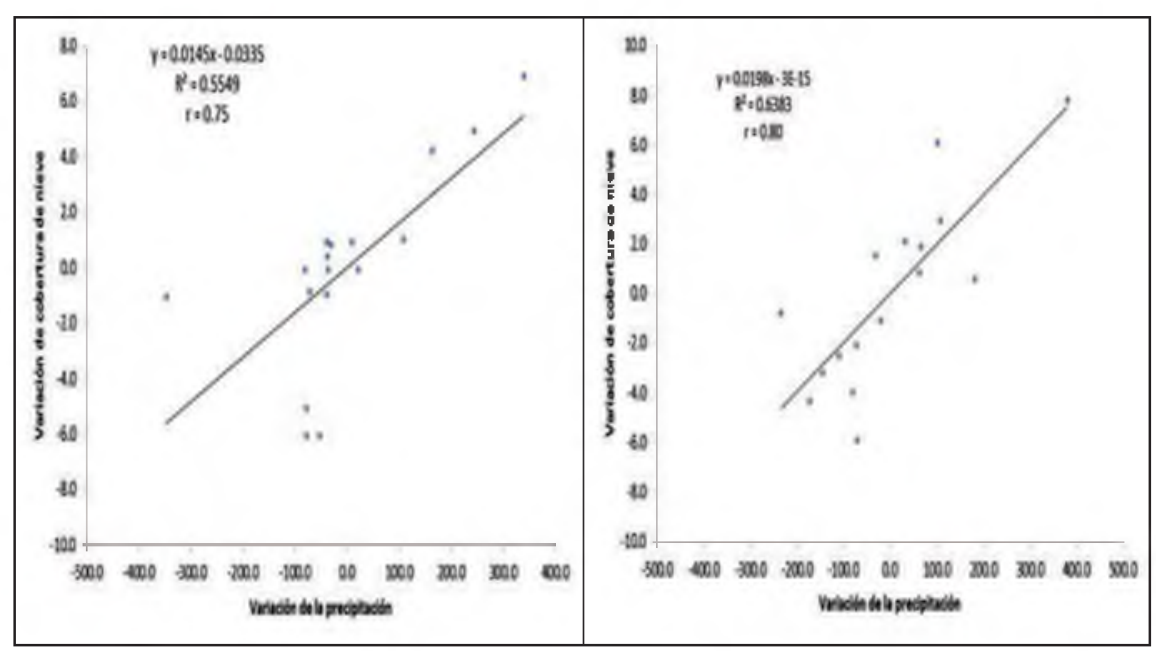

Figura $N^{\circ}$ 6: Línea de regresión lineal entre las variaciones de la precipitación y la variación de la cobertura de nieve del glaciar Pariaqaqa y Huaytapallana.

periodos deficitarios por presentar valores por debajo de su patrón o normal pluviométrico.

Figura $\mathrm{N}^{0} 7,8,9$ y 10 . Observaciones comparativas entre dos momentos temporales de imágenes satelitales de las variaciones de la cobertura de masa glaciar del nevado del Huaytapallana que corresponde a los ciclos hidrológicos del 2009-2010 y 2011 - 2012. También se presenta la variación del régimen pluviométrico que
2012 (figura 11). También se analiza las imágenes satelitales del año 2010 y del 2012 (figura 12) y se compara con los puntos de tendencia registrada. Además se presentan en la misma línea de tendencia las imágenes de satélite que corresponden al periodo del 2010 y al periodo final de la evaluación del 2012.

Ambas imágenes constituyen las evidencias empíricas del efecto de las anomalías climáticas en la cobertura 


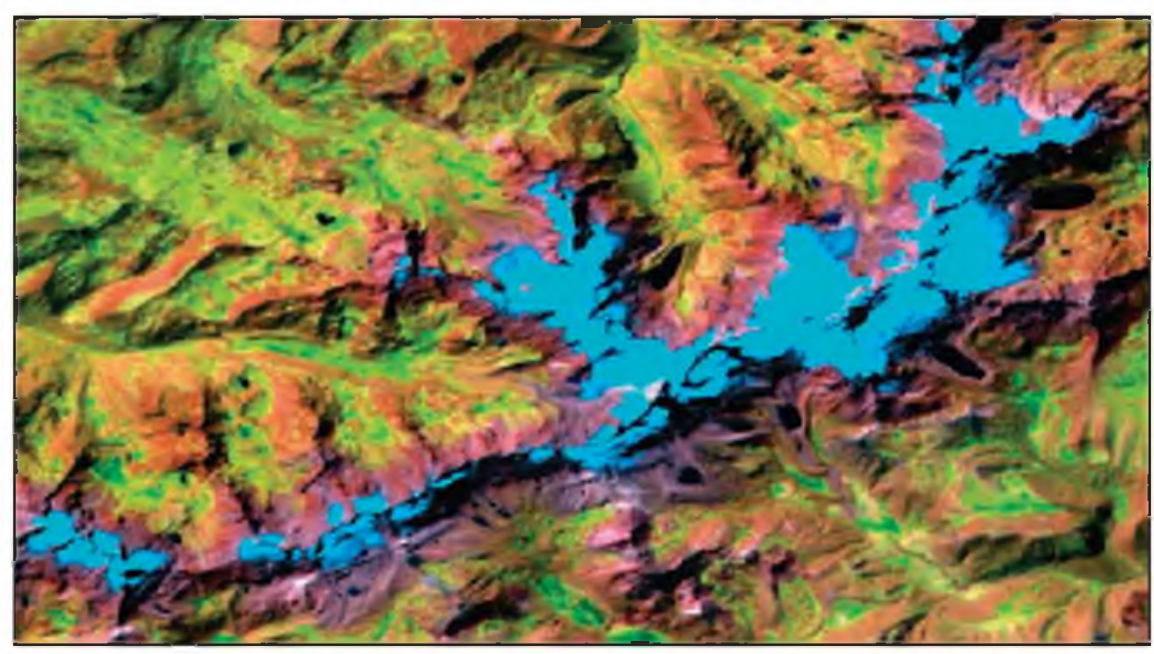

Figura $N^{\circ} 7$ : Imagen satelital de junio del 2010

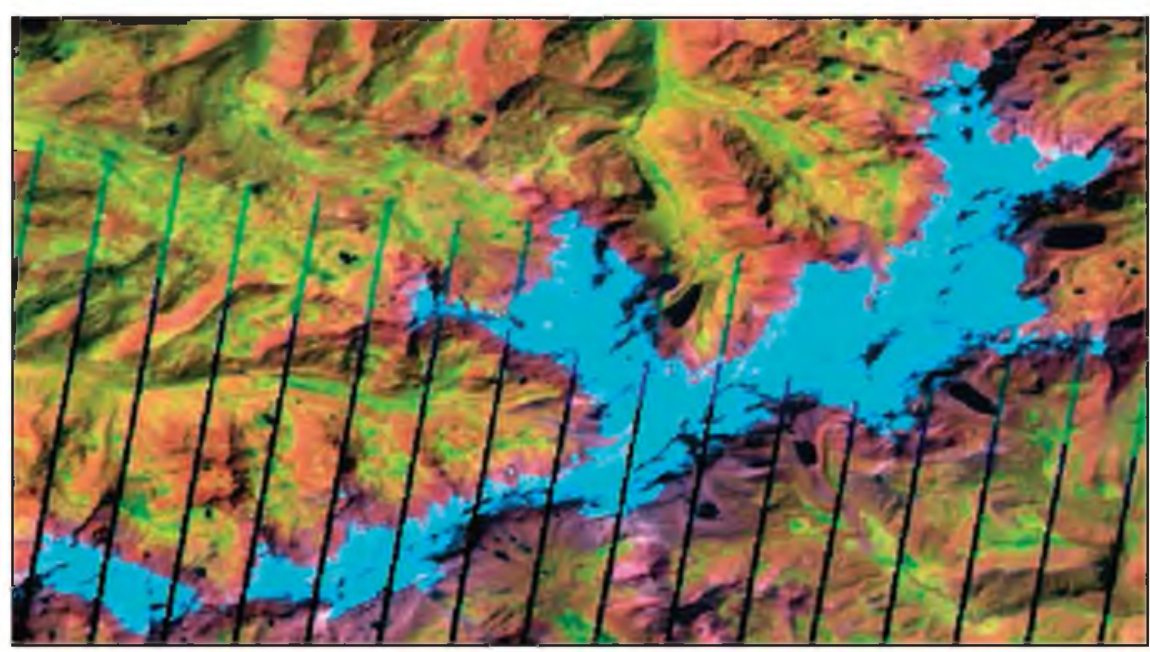

Figura $N^{\circ} 8$ : Imagen satelital de junio del 2012.

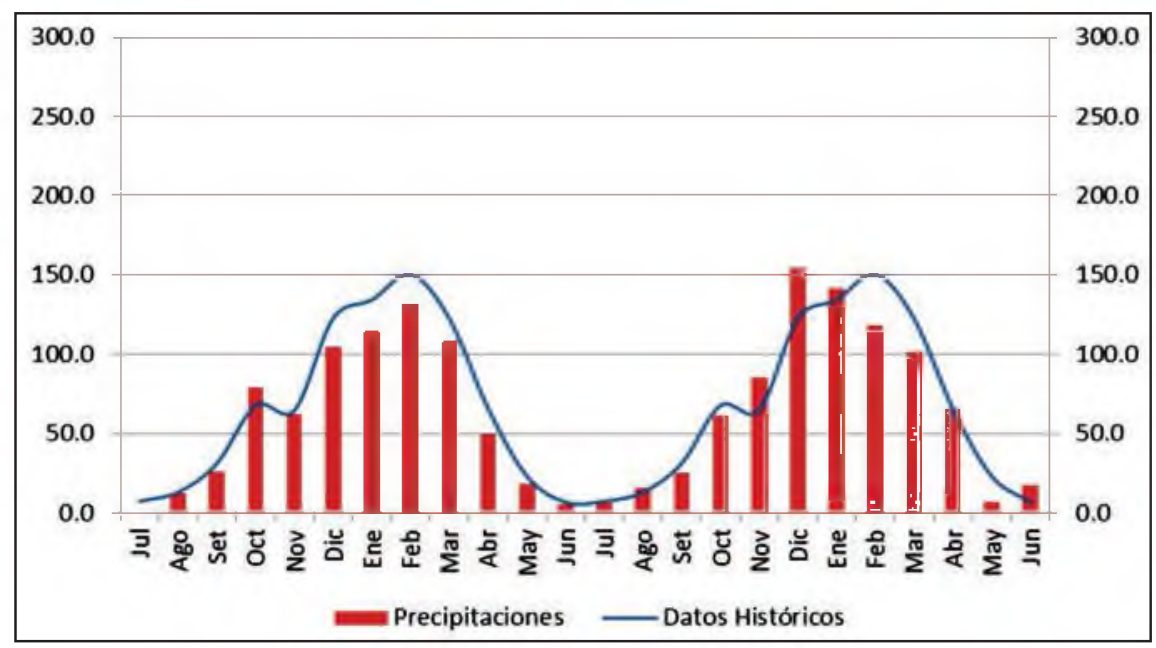

Figura $N^{\circ}$ 9: Régimen pluviométrico 2009-2010. 
del manto de nieve del glaciar por cambios en el régimen pluviométrico.

Figura $N^{\circ} 11$ y 12. Puntos que indican la cobertura de la masa glaciar desde el año 1961, realizado mediante fotografía aérea hasta el año 2012 realizado mediante imágenes satelitales. Se presenta una línea de tendencia negativa hasta el año 2010 y un cambio o recuperación durante el año 2011 y 2012. principal factor de cambios en el manto de nieve. En el glaciar del Huaytapallana (figura 7 y 8 ) el coeficiente de determinación es de 0,63 que explica el efecto de las anomalías climáticas en la cobertura del manto de nieve. Estos resultados confirman las conclusiones del estudio de López et al (16), quienes afirman que las variaciones en las precipitaciones son el principal factor de cambio en la cobertura de nieve del glaciar Huaytapallana.

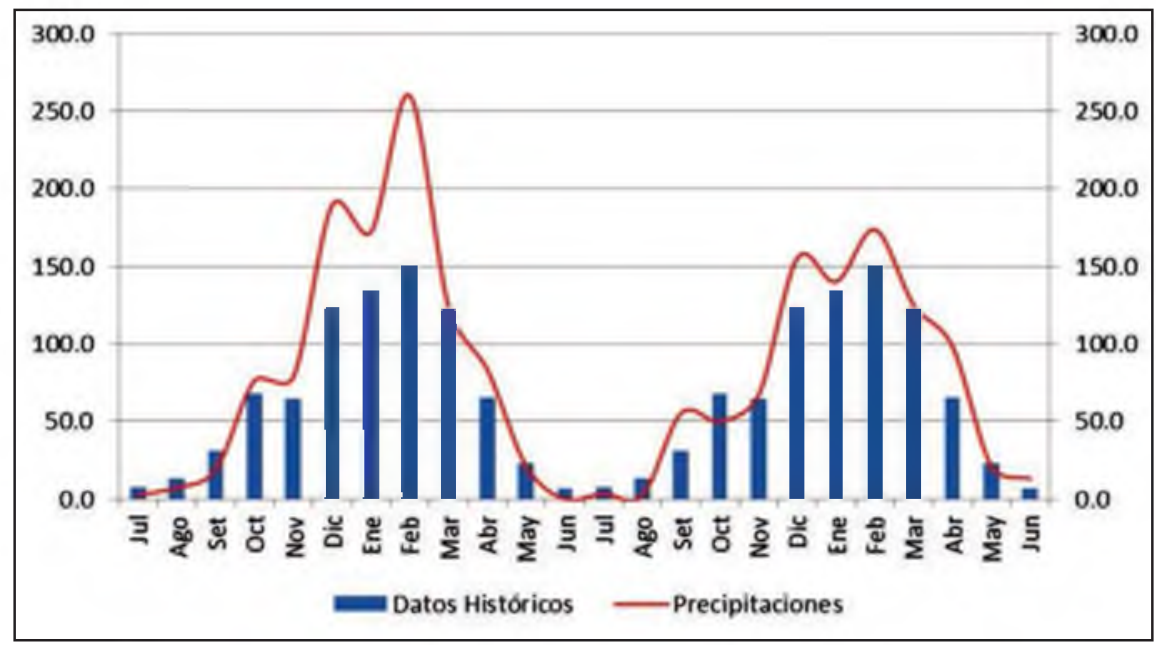

Figura N 10: Régimen pluviométrico 2011-2012.

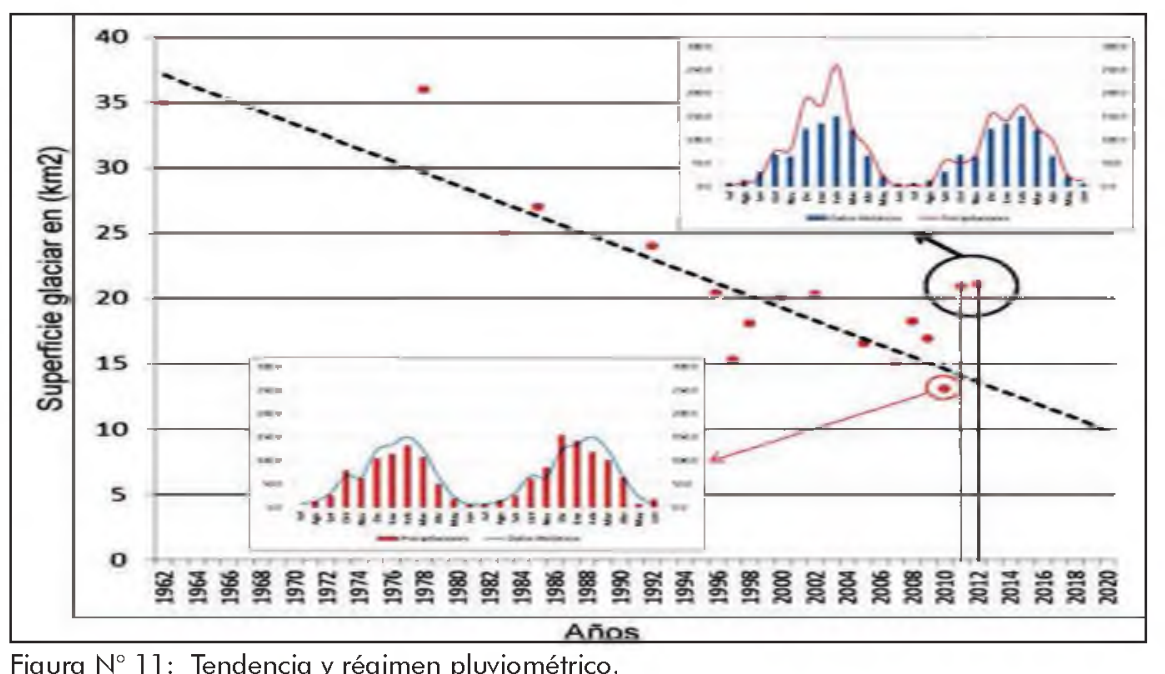

\section{DISCUSIÓN}

Las anomalías climáticas tienen un efecto en la cobertura del manto nieve de los glaciares que se encuentran en las cordilleras de los andes centrales del Perú. El glaciar del Pariaqaqa (figura 6) tiene un coeficiente de determinación de 0,55 que indica que las anomalías presentadas en las precipitaciones influyen en la cobertura de nieve; esto constituye el
Además el manto de nieve que cubre los glaciares Pariaqaqa y Huaytapallana, están condicionados por la variabilidad del clima que modifica el régimen y la estacionalidad del manto de nieve, esto refuerza los estudios de Lagos (23) quién afirma que la variabilidad climática constituye un mecanismo importante de carga y recarga de los mantos de nieve. También Ames y Francou (8) mencionan los efectos que tienen la variabilidad climática en los mantos de nieve anual. Viulle y Bradley (12) aclaran que la variabilidad 
climática está condicionada por los cambios en la atmósfera.

En los glaciares del Pariaqaqa y Huaytapallana se encontró dos variaciones en la cobertura del manto de nieve de mayor intensidad (figura 5). Estas variaciones dependen de los cambios en la circulación atmosférica del Atlántico que condiciona el comportamiento del clima en un periodo seco y otro húmedo como menciona Espinoza et al. (27). Los cambios en la circulación del Pacífico que se manifiesta en las estacionalidades (otoño, invierno y primavera) influyen en menor intensidad en el comportamiento del manto de nieve del glaciar Pariaqaqa pero no del glaciar Huaytapallana como también lo reporta Brecher (28).

Estos comportamientos diferentes en la variabilidad climática indican la importancia que tiene la subsidencia del pacífico sur en el glaciar Pariaqaqa. La estación de invierno no es totalmente seco debido a dos años muy secos en el glaciar Pariaqaqa y tres años en el glaciar Huaytapallana que se asocia a la desglaciación significativa de muchos glaciares como lo afirma Rabatel (20).

El periodo del año 2010, se observa como el año extremadamente húmedo para ambos glaciares (Figura 4). Espinoza et al (27) asocia el enfriamiento de la atmósfera con la presencia del fenómeno de la niña. Esta anomalía del clima positivo, ayudó a aumentar el volumen de los mantos de nieve en ambos glaciares. Además en el glaciar Pariaqaqa se presentaron dos años considerados muy húmedos, mientras que en el glaciar Huaytapallana se registró únicamente un año considerado como muy húmedo. Estas anomalías positivas son favorables para aumentar la cobertura del manto de nieve.

En el glaciar Pariaqaqa se presentan más fenómenos atípicos en los meses de diciembre, enero, febrero y

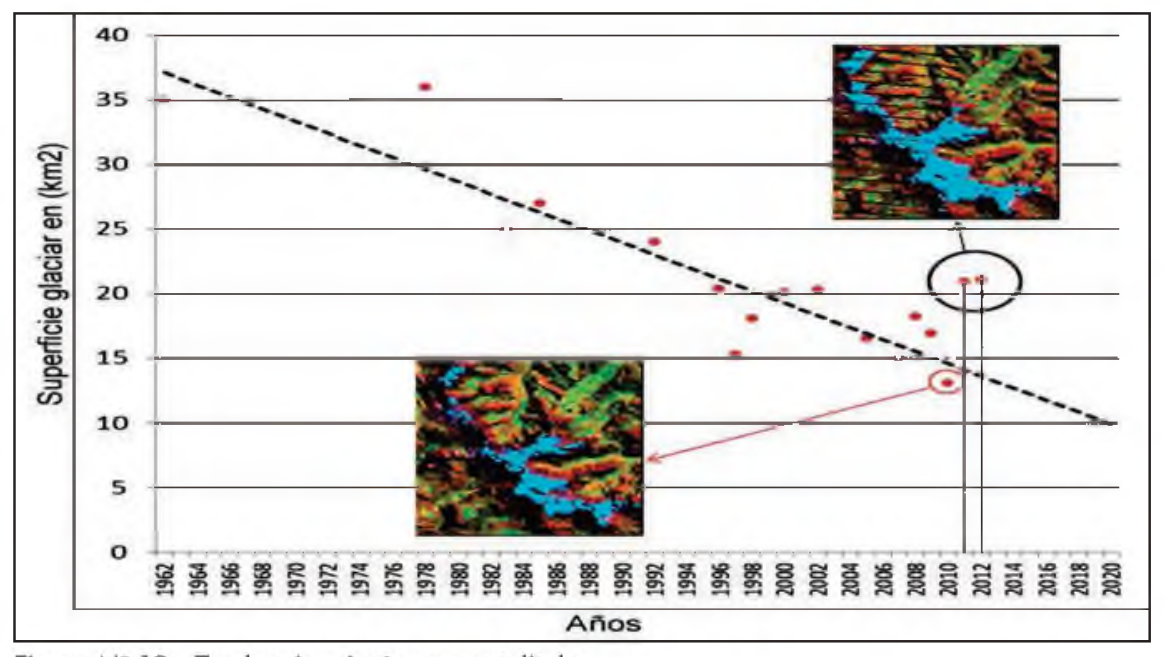

Figura $N^{\circ}$ 12: Tendencia e imágenes satelitales.

la contribución húmeda del Anticiclón del Pacífico Sur (SEPA) como la menciona Schulz et al (29). Además la variabilidad intraestacional que se presenta cada dos y cuatro meses ayuda en la conservación de grandes flujos de mantos de nieve. Mientras que el glaciar Huaytapallana no tiene esa contribución adicional.

En la serie de análisis de anomalías secos o extremadamente secos. El periodo del año 1991 se considera como un año extremadamente seco para ambos glaciares (Figura 3). Esto constituye el único año que coinciden en el análisis de periodos extremadamente secos. La cobertura del manto de nieve de ambos disminuyó considerablemente hasta dejar expuesto el hielo glaciar en la temporada de humedad. El déficit de precipitación se asocia a un cambio en las condiciones de circulación global debido a la presencia del fenómeno del niño como lo da a conocer Viulle (1). Posteriormente se observa marzo que coincide con la temporada de precipitaciones (figura 5). Se observa variaciones positivas hasta el doble de su normal climática que repercute en mayor acumulación y mayor área cubierta de nieve. En el glaciar Huaytapallana se observa pocos fenómenos atípicos positivos, todos los eventos se encuentran dentro del rango de su variabilidad como lo menciona Arroyo et al (22).

Con respecto a los cambios observados en la cobertura del manto de nieve del glaciar Huaytapallana debido a la anomalía climática de los años 2010 y 2012, se atribuye al fenómeno de la niña del nivel moderado. Este cambio en la circulación atmosférica permitió obtener una mayor cobertura de nieve en ambos glaciares como lo menciona Wilks (30).

En el glaciar del Huaytapallana (figura $N^{\circ} 7,8,9 y$ 10). La imagen satelital muestra la cobertura que 
Tabla N ${ }^{\circ}$ : Resultado de variaciones de temperatura, precipitación y cobertura del manto de nieve del glaciar Huaytapallana.

\begin{tabular}{|c|c|c|c|c|c|c|c|}
\hline \multirow{2}{*}{$\begin{array}{l}\text { Variables } \\
\text { Variaciones con respecto a su media }\end{array}$} & \multicolumn{2}{|c|}{$\begin{array}{l}\text { Años } \\
\text { Cálidos }\end{array}$} & \multirow[t]{2}{*}{ Total } & \multicolumn{2}{|c|}{$\begin{array}{l}\text { Años } \\
\text { Templados }\end{array}$} & \multirow[t]{2}{*}{ Total } & \multirow[t]{2}{*}{ Diferencias } \\
\hline & 2009 & 2010 & & 2011 & 2012 & & \\
\hline Temperatura en grados centígrados $\left({ }^{\circ} \mathrm{C}\right)$ & 0,27 & 0,75 & 0,75 & 0,11 & 0,14 & 0,13 & 0,39 \\
\hline Precipitación en milímetros de lluvia (mm) & $-67,4$ & $-84,6$ & $-84,6$ & 334,3 & 213,2 & 547,5 & 699,5 \\
\hline $\begin{array}{l}\text { Cobertura glaciar del nevado Huaytapallana } \\
\text { en km2 }\end{array}$ & $-2,1$ & $-5,9$ & $-5,9$ & 3,9 & 5,1 & 9,0 & 11,0 \\
\hline
\end{tabular}

diferencia al año 2010. Esto se puede explicar mediante los cambios observados en la temperatura y la precipitación desde el año 2009 hasta el año 2012 (Tabla 2). Una anomalía negativa (años 2009 y 2010) puede reducir el glaciar hasta $8,0 \mathrm{~km} 2$. Mientras una anomalía positiva puede favorecer a la cobertura del manto de nieve hasta 9,0 km2. Esto lo reporta Kaser y Osmaston (9). Esta variación permitió modificar la tendencia de la cobertura de mantos de nieve (figura $N^{\circ} 11$ y 12) para luego retornar a su tendencia negativa.

\section{Agradecimientos}

A Rosalind Arroyo y Edsel Arroyo por la colaboración en el tratamiento y análisis de datos de campo. A Wyler Espeza y Frans Cornejo por su apoyo en los trabajos de campo. Al IGP por su apoyo científico en la investigación y finalmente a Domingo Rosales por contribuir con algunas metodologías.

\section{REFERENCIAS BIBLIOGRÁFICAS}

1. Viulle M, Burns SJ, Taylor BL, Cruz FW, Bird BW, et al. A review of the South American monsoon history as recorded in stable isotopic proxies over the past two millennia. Clim. Past. 2012; 8: 1309 1321.

2. Thompson L, Mosley-thompson E, Davis M, et al. Tropical glacier, records and indictors of climate change, are disappearing globally. Annals of Glaciology. 2011 ; 52(59): 23-34.

3. Francou B, Ribstein P, Wagnon P, Ramirez E, Pouyaud B. Glaciers of the tropical Andes: indicators of global climate variability. In: Huber U, Bugmann HKM, Reasoner M.A. Global Change and Mountain Regions: An Overview of Current Knowledge, Vol. 23. Dordrecht: Springer; 2005.

4. Bury JT, Mark BG, McKenzie JM, French A, Baraer, et al. Glacier recession and human vulnerability in the Yanamarey watershed of the Cordillera Blanca, Peru. Climate Change. 2011 ; 105: 179-206.

5. Georges C. 20th-Century Glacier Fluctuations in the Tropical Cordillera Blanca, Perú. Arctic,
Antarctic and Alpine Research. 2004; 36 (1): 100 107.

6. Francou B, Vuille M, Wagnon P, Mendoza J, Sicart JE. Tropical climate change recorded by a glacier in the central Andes during the last decades of the twentieth century: Chacaltaya, Bolivia, $16^{\circ} \mathrm{S}$. J. Geophys. Res. 2003; 108(D5): 4154-4162.

7. Kaser G, Georges C. On the mass balance of low latitude glaciers with particular consideration of the Peruvian Cordillera Blanca. Geografiska Annaler. 1999; 81(4); 643-651.

8. Vuille M, Bradley RS, Werner M, Keimig F. 20th century climate change in the tropical Andes: observations and model results. Clim. Chang. 2003; 59(1-2): 75-99.

9. Kaser G, Osmaston H. Tropical Glaciers. Cambridge: Cambridge University Press; 2002.

10. Racoviteanu AE, Manley WF, Arnaud Y, Williams MW. Evaluating digital elevation models for glaciologic applications: An example from Nevado Coropuna, Peruvian Andes. Glob. Planet. Chang. 2007; 59(1-4) $110-125$.

11. Mark BG. Tracing tropical Andean glaciers over space and time: some lessons and transdisciplinary implications. Global and Planetary Change. 2008; 60(1-2): 101-114.

12. Bradley RS, Keimig FT, Diaz HF. Projected temperature changes along the American cordillera and the planned GCOS network. Geophysical Research Letters. 2004; 31 (L16210): 1-4.

13. Chevalier P, Pouyand B, Suarez W, Condom T. Climate change threats to environment in the Tropical Andes: glaciers and water resources. Reg. Environ. Chang. 2011; 11(1): 179-187.

14. Sicart JE, Wagnon P, Ribstein P Atmospheric controls of heat balance of Zongo Glacier $\left(16^{\circ} \mathrm{S}\right.$, Bolivia). J. Geophys. Res. 2005; 110(D12106):117.

15. Zubieta R, Lagos $\mathrm{P}$ Cambios de la superficie glaciar en la cordillera Huaytapallana: periodo 1976 - 2006. En: Cambio climático en la cuenca del Río Mantaro: Balance de 7 años de estudio. Lima: Instituto Geofísico del Perú; 2010.

16. López-Moreno J, Fontaneda J, Bazo J, Revuelto J, Azorin-Molina C, Valero-Garcés E. et al. Recent glacier retreat and climate trend in Cordillera 
Huaytapallana, Peru. Global and Planetary Change. 2014; 112:1-11.

17. Ames A, Francou B. Cordillera Blanca: Glaciares en la Historia. Bull. Inst. fr. études andines. 1995, $24(1): 37-64$

18. Fraser B. Melting in the Andes: Goodbay glaciers. Nature. 2012; 491: 180-182.

19. Mark BG, Seltzer GO. Evaluation of recent glacier recession in the Cordillera Blanca, Peru (AD 1962-1999): spatial distribution of mass loss and climatic forcing. Quat. Sci. Rev. 2005; 24: 2265 2280.

20. Rabatel A, Francou B, Soruco A, Gomez J, Cáceres $B$, et al. Current state of glaciers in the tropical Andes: a multi-century perspective on glacier evolution and climate change. Cryosphere. 2013; 7: 81-102.

21. Portocarrero C. Retroceso de glaciares en el Perú: consecuencias sobre los recursos hídricos y los riesgos geodinámicos. Bull. Institut fr. études andines. 1995 ; $24(3)$ : 697-706.

22. Arroyo J. Tendencias y cambio del clima del valle del Mantaro mediante los análisis de índices de precipitación efectiva y temperatura eficiente. Apunt. cienc. soc. $2011 ; 1(1), 45-54$.

23. Lagos P, Silva Y, Nickl E. El Niño y la precipitación en los Andes del Perú. Bol. Soc. Geol. 2005; 6: 7-23.

24. McFadden EM, Ramage J, Rodbell DT. Landsat TM and ETM+ derived snowline altitudes in the Cordillera Huayhuash and Cordillera Raura, Peru, 1986-2005. The Cryosphere. 2011 ; 5: 419-430.

25. ElectroPerú. Boletin Anual de precipitaciones y análisis hidrológico de la Cuenca del Mantaro. Lima; 2013.

26. Nuñez SE, Nuñez LN, Podesta GP, Skansi M. El índice estandarizado de precipitación como herramienta para la caracterización y el monitoreo de la sequía: una prueba de concepto. CONGREMET IX, 9th. Argentina Congress of Meteorology. Buenos Aires: 2005.

27. Espinoza JC, Ronchail J, Guyot J, Junquas C, Vauchel P, Lavado $W$, et al. Climate variability and extreme drought in the upper Solimỗes River (Western Amazon Basin): Understanding the exceptional 2010 drougt. Geophisical Research Letters. $2011 ; 38(13): 1-16$.

28. Brecher HH, Thompson LG. Measurement of the retreat of Qori Kalis Glacier in the Tropical Andes of Peru by terrestrial photogrammetry. Photogramm. Eng. Remote Sens. 1993; 59: 1017-1022.

29. Schulz N, Boisier P, Aceituno P Climate Change Along the Arid Coast of Northern Chile. International Journal of Climatology. 2011; 32(12): 1803-1814.

30. Wilks DS. Statistical Methods in the Atmospheric Sciences. New York: Cornell University; 2006. 